Boise State University

ScholarWorks

Genetic Counseling Faculty Publications and

Presentations

$10-2020$

\title{
Facing the Challenge of Genetic Counselors' Need for Rapid Continuing Education About Genomic Technologies
}

Kelly D. Farwell Hagman

Ambry Genetics

Devon Lamb Thrush

Ambry Genetics

Samantha Freeze

InformedDNA

Darnelle L. Dorsainville

GeneDx

Jennifer Eichmeyer

Boise State University

See next page for additional authors

This is an author-produced, peer-reviewed version of this article. The final, definitive version of this document can be found online at Journal of Genetic Counseling, published by Wiley on behalf of the National Society of Genetic Counselors. Copyright restrictions may apply. https://doi.org/10.1002/jgc4.1213. The content of this document may vary from the final published version. 


\section{Authors}

Kelly D. Farwell Hagman, Devon Lamb Thrush, Samantha Freeze, Darnelle L. Dorsainville, Jennifer

Eichmeyer, Kimberly C. Banks, and Genomic Technologies Special Interest Group of the National Society of Genetic Counselors 
This is an author-produced, peer-reviewed version of this article. The final, definitive version of this document can be found online at Journal of Genetic Counseling, published by Wiley. Copyright restrictions may apply. https://doi.org/10.1002/jgc4.1213

\title{
Facing the Challenge of Genetic Counselors' Need for Rapid Continuing Education About Genomic Technologies
}

\author{
Kelly D. Farwell Hagman* \\ Ambry Genetics \\ Department of Clinical Genomics \\ Aliso Viejo, CA \\ kfarwell@ambrygen.com \\ Devon Lamb Thrush \\ Ambry Genetics \\ Department of Clinical Genomics \\ Aliso Viejo, CA \\ Samantha Freeze \\ InformedDNA \\ St. Petersburg, FL \\ Darnelle L. Dorsainville \\ GeneDx \\ Gaithersburg, MD \\ Jennifer Eichmeyer \\ Boise State University \\ Boise, ID \\ Kimberly C. Banks \\ (on behalf of the Genomic Technologies Special Interest Group of the National Society of Genetic Counselors) \\ Guardant Health \\ Department of Medical Affairs \\ Redwood City, CA
}

\begin{abstract}
The last couple of decades have seen the rapid advancement of genomic technologies (GT) and their equally rapid adoption into clinical testing. Regardless of specialty, all genetic counselors are unified by the fundamental goal to aid in diagnosing patient's genetic disease underscoring the importance for genetic counselors to maintain an in-depth understanding of GT. The National Society of Genetic Counselors' (NSGC) GT Special Interest Group conducted an online survey of NSGC members to assess current genomic technologies knowledge gaps. A total of 171 individuals from a variety of primary work settings completed the survey sufficiently to be included in the analysis. The majority of respondents received their degree in genetic counseling in more recent years $(2000-2015)$. On average across all technologies, $>70 \%$ of respondents deemed knowledge of GTs as important for successful job performance, 55\% responded that additional job training in GTs is needed to successfully perform job functions, and only $28 \%$ responded that graduate training in GTs was good. Overall, the data show that participating genetic counselors perceive that their knowledge of GTs is inadequate while it is a key component of their jobs. These results have implications both for training programs and for continuing education efforts. These data can be used as a starting point for additional research into GT educational needs of genetic counselors.
\end{abstract}

Keywords: genomic technologies, genetic counselor education, needs assessment, continuing education, Next-Gen Sequencing (NGS) 
This is an author-produced, peer-reviewed version of this article. The final, definitive version of this document can be found online at Journal of Genetic Counseling, published by Wiley. Copyright restrictions may apply. https://doi.org/10.1002/jgc4.1213

\section{Introduction}

The last several decades has seen an explosion in new and emerging genomic technologies (Cunha, 2017; Galas \& McCormack, 2003) making the need for continuing education for genetic counselors a constant and difficult task. Additionally, the past decade has seen an unprecedented expansion in roles of genetic counselors outside of the traditional patient-counselor clinical role to settings such as laboratory, research, marketing, insurance, and bioinformatics (Christian, Lilley, Hume, Scott, \& Somerville, 2012; McWalter et al., 2018; Radford, Prince, Lewis, \& Pal, 2014; Swanson, Ramos, \& Snyder, 2014; Wain, 2018; Zetzsche, Kotzer, \& Wain, 2014). In fact, it is anticipated that genetic counselors will sit on the frontline of precision health given that genetic counseling "is technology-driven and an individual-centered approach, exactly the same properties of what is now called "precision medicine"" (Bamshad, Magoulas, \& Dent, 2018). Starting as early as 2012, discussion emerged about how genetic counselors can adequately incorporate next-generation sequencing (NGS) into clinical practice (Hooker, Ormond, Sweet, \& Biesecker, 2014; Roche, 2012; Wicklund \& Trepanier, 2014).

Regardless of practice specialty, genetic counselors are unified by the fundamental goal to aid in diagnosing a patient's genetic disease. The first domain of the core competencies for genetic counselors trained in United States/Canadian accredited programs that "an entry-level provider must demonstrate to successfully practice as a genetic counselor" is titled "genetics expertise and analysis" (www.gceducation.org/practice-based-competencies/). Specifically, a genetic counselor should "demonstrate and utilize a depth and breadth of understanding and knowledge of genetics and genomics core concepts and principles" including applying this knowledge to "genetic testing and test report interpretation." Interpretation of genetic test results requires a basic understanding of the underlying technologies and these tests typically use the most recent and emerging technologies. Further, as direct to consumer (DTC) offerings continue to gain popularity, genetic counselors will be called upon to help interpret the results. A recent study showed that up to $40 \%$ of variants identified in DTC testing are false positives, generally due to limitations in the particular technologies used (Tandy-Connor et al., 2018). Therefore, it is imperative that genetic counselors maintain a clear and thorough understanding of genomic technologies (GT) and that efforts be made by graduate school programs and governing organizations to assist in GT continuing education.

There has been ample discussion about genetics education of non-genetics health care providers (Baars, Henneman, \& Ten Kate, 2005; Blaine et al., 2008; Farndon \& Bennett, 2008; Gaff, Williams, \& McInerney, 2008; Hunter, Wright, Cappelli, Kasaboski, \& Surh, 1998; Kirk, Tonkin, \& Burke, 2008; Masny, Ropka, Peterson, Fetzer, \& Daly, 2008; Metcalfe, Haydon, Bennett, \& Farndon, 2008; Suchard, Yudkin, Sinsheimer, \& Fowler, 1999). In fact, a systematic review of the literature relating to primary care providers' perceived barriers against provision of genetic services found that knowledge about genetics and genetic risk assessment was among the top four most common barriers (Mikat-Stevens, Larson, \& Tarini, 2015). In 2010, Calzone et al. detail the need for providing genomic/genetic education for nurses in order to facilitate the ability of the United States health care system to better promote health and manage disease (Calzone et al., 2010). In the current study, we aimed to assess whether further genetics education is needed even among genetic counselors. Specifically, we aimed to assess current genomic technologies knowledge gaps of practicing genetic counselors.

\section{Methods}

\section{$\underline{\text { Participants and Procedures }}$}

The GT Special Interest Group (SIG) of the National Society of Genetic Counselors (NSGC) created an electronic survey using SurveyMonkey ${ }^{\circledR}$ and distributed it to the NSGC membership via multiple mechanisms in March and April 2016: NSGC "Link" monthly member e-newsletter on March 11, 2016; discussion forums of NSGC SIGs via SIG chairs on March 22, 2016; NSGC general "all members" discussion forum on April 7, 2016. It is estimated that the survey was sent to approximately 4,000 individuals via these methods. Confirmation of distribution was received from the Health Information Technology and Neurogenetics SIG chairs. Prior to administration of the survey, the GT SIG chairs verbally alerted various members about the anticipated survey and encouraged participation. The survey remained open until May $1^{\text {st }}$, 2016 (Supplemental Table 1) and no reminder emails were delivered. Any NSGC member was eligible to take the survey, regardless of specialty, board-certification, or current practicing status. The research is exempt from the Office for Human Research Protections Regulations for the Protection of Human Subjects under category $46.104(\mathrm{~A})$. 
This is an author-produced, peer-reviewed version of this article. The final, definitive version of this document can be found online at Journal of Genetic Counseling, published by Wiley. Copyright restrictions may apply. https://doi.org/10.1002/jgc4.1213

\section{$\underline{\text { Instrumentation }}$}

We developed a questionnaire to assess current GT knowledge gaps (Supplemental Table 1). The authors reviewed the underlying technologies used among commonly available genetic tests on the market at the time of the study and identified twelve core technologies. These twelve core GTs are listed in Figure 1. The questionnaire contained three questions about each core technology, demographic items, and a comment section. The three core technologies questions gauged the participants' assessment of how important each of the core technologies is to successful job performance (Likert-type scale: 1 = Not important, 5 - Very important), how much additional training is need to adequately and successfully perform his/her current job (Likert-type scale: $1=$ No training needed, $4=\mathrm{A}$ high level of training needed), and how adequate the level of education obtained during graduate school was (Likert-type scale: $1=$ Very poor, $5=$ Very good, $0=$ N/A, no training received, respondents who selected N/A were removed from analyses of this item). The demographics section assessed the primary work setting, specialty, and year of graduation from graduate training in genetic counseling.

\section{$\underline{\text { Data Analysis }}$}

Descriptive statistics were calculated for each survey response. Respondents could choose multiple specialties, and specialty distribution among respondents was compared to the 2016 professional status survey (PSS; https://www.nsgc.org/d/do/6432) specialty distribution using one-way ANOVA to determine if representation of the greater membership was obtained. Specialty was not used in the analysis of responses to the three core technology questions. Instead, respondents were classified by primary work setting into one of three categories: clinical, laboratory, or other (Table 1). Pairwise comparisons using Fisher's exact 2x2 2-tailed contingency calculations were performed to compare responses for each technology by primary work setting; specifically, responses by participants from a clinical specialty were compared to those from a laboratory setting and to those from an "other" setting and participants from a laboratory setting were compared to those from an "other" setting. For the query regarding graduate school training, respondents who selected N/A-no training received were removed from the statistical calculations. Free text response data were analyzed using an inductive thematic analysis and basic descriptive statistics. Each free text response was evaluated by a single coder (SF) who generated and assigned initial themes to each response. Initial themes were then reviewed for agreement by a second coder (KB) who generated and assigned master themes to further categorize the free text responses. Both coders provided final review and reconciliation of the initial and master themes and were in agreement with final coded data set. Only the percentage of total respondents who contributed free text responses for each thematic category was reported. Inter-rater agreement (kappa statistic and p-value) were not calculated.

\section{Results}

\section{Demographics}

A total of 183 individuals responded to the survey. The response rate is estimated to be $4.6 \%(183 / \sim 4,000)$. Twelve surveys included no response to all twelve queries for at least one of the three main GT questions and were therefore eliminated from further analysis, resulting in 171 surveys included in data analysis. These 171 participants worked primarily in clinical settings (52\%) followed by laboratory settings (36\%) (Table 1). Most respondents (83\%) graduated from a genetic counseling master's program 2000-2015 (Table 1, Supplemental Figure 1). The distribution of respondents per graduation year was not significantly different from the graduation year distribution among 2016 NSGC PSS respondents $(\mathrm{p}=0.63$ ). The respondents' reported specialty also did not differ from the $2016 \mathrm{PSS}(\mathrm{p}=0.89$ ). Further, there was no difference in the distribution of graduation years based on work setting (clinical, laboratory, other) $(\mathrm{p}=0.65)$. Survey respondents could choose more than one specialty; the most common specialties were cancer (93 respondents; 54\%), genetic testing (43 respondents; 25\%), prenatal (30 respondents; 17.5\%), laboratory (28 respondents; $16 \%$ ), and general genetics (24 respondents; $14 \%)$.

\section{Genomic Technologies Knowledge and Needs}

Across the twelve GT categories, the percentage of respondents who reported that knowledge of the technologies is "important" or "somewhat important" in order to successfully perform his/her job ranged from $46.2 \%$ to $98.8 \%$ (average $=73.5 \%)$ (Table 2, Figure 1). NGS ranked the highest with $98.8 \%$ identifying it as important for job 
This is an author-produced, peer-reviewed version of this article. The final, definitive version of this document can be found online at Journal of Genetic Counseling, published by Wiley. Copyright restrictions may apply. https://doi.org/10.1002/jgc4.1213

performance, followed by Sanger Sequencing (94.2\%), cfDNA-tumor (93\%), and PGS/PGD (84.2\%). The lowest ranked technology was bioinformatics, yet still almost half of respondents deemed it important for successful job performance $(46.2 \%)$.

Across the twelve GT categories, the percentage of respondents who reported that "some training" or "a high level of training" is needed for adequate job performance ranged from $28.2 \%$ to $76.9 \%$ (average $=54.9 \%$ ) (Table 2, Figure 1). Ranked the highest in need of training were cfDNA-tumor (76.9\%), NGS-based CNV detection (75.1\%), PGS/PGD (74.7\%), and PCR/DNA amplification (72.2\%). The lowest ranked technology was on-array capture methods, however nearly a third of respondents (28.2\%) indicated that further training is needed on this technology. In addition, $28.6 \%$ of respondents who provided free text comments (14/49) and suggestions expressed a desire for additional training regarding specific genomic technologies.

Overall across the twelve GT categories, only an average of $28.1 \%$ of respondents reported that graduate school training in the GTs was either "good" or "very good." (Table 2, Figure 1). Further, 28.6\% of free text comments and suggestions expressed a personal or perceived impression that graduate school training in GTs did not meet what respondents viewed as adequate for job performance. The technologies which ranked the lowest in terms of having received good/very good training in graduate school were cfDNA-tumor (2.9\%), in-solution capture methods (5.3\%), bioinformatics $(8.8 \%)$, and on-array capture methods (10.5\%). Although not the lowest ranking, a minority of respondents reported good/very good training for NGS-based CNV detection (16.4\%), NIPT/NIPS (18.1\%), NGS (23.4\%), or MLPA $(30.4 \%)$. The technology ranked the best in terms of graduate school training was Sanger Sequencing (68.4\%) followed by PCR/DNA amplification (66.1\%), arrayCGH (39.8\%), and PGD/PGS (47.4\%).

NGS was ranked the most important technology needed for successful job performance (98.8\%), yet $43 \%$ of respondents reported that additional training is needed for adequate job performance and only $23 \%$ felt that graduate school training was good/very good. Those that reported inadequate training in NGS clustered in the earlier graduating classes (Table 3). The technology which emerged as the most discrepant with regard to importance for job performance versus training needed was cfDNA-tumor with $93 \%$ of respondents reporting that the technology is important for successful job performance, yet $76.9 \%$ feel additional training is needed and only $2.9 \%$ felt that graduate school training was sufficient.

\section{Differences by Primary Work Setting}

Participants from a laboratory setting were significantly more likely to deem bioinformatics, aCGH, and PGS/PGD important for successful job performance as compared to participants from a clinical setting ( $<<0.01$; Table 2). Conversely, participants from a clinical setting were significantly more likely to deem in-solution sequence capture methods important to successful job performance as compared to participants from a laboratory setting $(\mathrm{p}<0.01)$. Participants from a clinical setting felt that graduate school training in NGS-based copy-number variation (CNV) detection was good as compared to participants from a laboratory setting $(\mathrm{p}<0.01)$. Participants from the nonclinical/non-laboratory (aka "other") setting felt that more training is needed in MLPA as compared to individuals in a laboratory setting $(\mathrm{p}<0.01)$. No other statistically significant differences by primary work setting were identified.

\section{Graduate School Training by Year of Graduation}

The level of reported training improved with more recent graduates. Across all twelve technologies, $93.9 \%$ graduates from the earliest group (1979-1989) felt that graduate school training was inadequate or that they did not receive training (Table 3, Supplemental Figure 2). Among graduates from 1990-1999, 2000-2009, and 2010-2015, 86.6\%, $62.9 \%$, and $37.4 \%$ felt that training was inadequate or that they did not receive training, respectively. Even among the most recent graduates (2010-2015), 37.4\% reported that training was "poor," "very poor," or absent on average across all technologies. The four technologies that ranked the poorest among recent graduates were NIPT/NIPS, insolution sequence capture methods, bioinformatics, and cfDNA-tumor with $79.2 \%, 71.8 \%, 60 \%$, and $38.9 \%$ of the respondents stating that training was inadequate or absent, respectively.

\section{Qualitative Analyses of Free Text Comments and Suggestions}

Of the 171 respondent surveys included in data analysis, 55 (32\%) provided supplemental free text comments and/or suggestions (Supplemental Table 2). Six of these responses were too brief to perform qualitative thematic analysis. The responses were comprised of mostly 1-2 sentence short answers intended to provide context to the respondent's 
This is an author-produced, peer-reviewed version of this article. The final, definitive version of this document can be found online at Journal of Genetic Counseling, published by Wiley. Copyright restrictions may apply. https://doi.org/10.1002/jgc4.1213

survey answers or provide a suggestion for additional GT training preferences. Of the 49 remaining participant responses, 10 key minor themes were identified (Table 4). These themes were then categorized into three higher themes; (1) training theme, (2) comparison ability theme and (3) other theme. The training theme was applied to responses where respondents indicated an impression about previously received training or the need/desire for additional GT training. The comparison ability theme was applied to responses where the respondent indicated a need/desire for additional training in how to evaluate appropriateness of various GTs and/or the ability to compare genetic testing laboratories and how to choose the "best" lab for their clinical needs. The other theme was applied to responses with low reporting percentage but that the researchers felt were valuable to overall interpretation of genetic counselor attitudes towards GT training. Overall, responses focused heavily on the themes of perception of inadequate genetic counselor training for GTs $(13 / 49 ; 26.5 \%)$, the desire for additional training regarding specific GTs (14/49; $28.6 \%)$ and how to evaluate the clinical appropriateness of various GTs and GT platforms $(14 / 49 ; 28.6 \%)$.

Some genetic counselors also indicated in free text responses the desire for additional training in specific genomic technologies. However, they also expressed the desire for less theoretical information and more practical education focused on information that can be applied in their clinical practice. For instance, one respondent stated that, during graduate school, she/he received "some education [regarding GTs], but at the time didn't know what was important for everyday use and what was background education, areas of importance are more clear now that I am in practice." This quote also reflects an additional theme of "on-the-job training" where respondents indicated a personal or perceived impression that the most useful education regarding GTs was gained after graduate school and during his/her career and in collaboration with other genetic counselors.

\section{Discussion}

In a commentary on genetic counseling in the genomic era, Wicklund and Trepanier state: "As new technology is adopted, it is critically important for program directors and practicing professionals to evaluate whether fundamental changes in genetic counselors' knowledge, skills, and attitudes, and ultimately genetic counseling practice are required" (Wicklund \& Trepanier, 2014). In this study, we provide quantitative data addressing these needs which demonstrate that indeed fundamental changes may be warranted.

The consistent rapid expansion of genomic technologies has led to the need for continuing education for genetic counselors. These survey data represent the first study to investigate genetic counselor self-assessment regarding GT knowledge gaps and training needs. The majority of respondents, across all specialties reported that knowledge of the core GTs is important for successful job performance, that additional training is needed, and that graduate school training was not adequate. Responses to this survey indicate that baseline education about genomic technologies via graduate programs is limited, which is not unexpected given the breadth of required and necessary medical genetics and clinical/psychosocial skills covered in the two-year masters' programs and the fast pace of implementation of new technologies. Genetic counseling program directors report that genomic medicine is either currently taught or under development and rank genomic technologies among the most important to include in genetic counseling curricula (Profato, Gordon, Dixon, \& Kwan, 2014). These data can serve to aid in shaping the training program curricula related to GTs. However, overall the data likely reflect the rapidly advancing and evolving molecular technologies which can more adequately and contemporaneously addressed via ongoing education opportunities. Webinars in particular offer rapid, up-to-date, low-cost opportunities for continuing education.

These results provide insight for both graduate school curricula and for continuing education outlets. For example, cell free analysis of tumor DNA emerged as the most immediate need given it scored lowest with regard to graduate school training but scored among the highest among knowledge most needed for successful job performance. Likewise, the technology that ranked the highest in importance for job performance was NGS, with $98.8 \%$ of respondents identifying this technology as important, yet less than a quarter felt that graduate school training on the topic was good/very good. Although only $43 \%$ identified that some/significant training in NGS is needed to more adequately perform their job, the overall importance for job performance and limited baseline training suggest that adjustments to future graduate curricula and greater allocation of continuing education resources to this topic would serve the genetic counseling community well.

Some differences were observed among counselors based on primary work setting. While at least two-thirds of laboratory counselors and clinical counselors felt that some training was needed to understand aCGH and PGS/PDG technologies, laboratory counselors were significantly more likely to report that understanding aCGH and PGS/PDG technologies were more important to successful job performance than clinical counselors. This result suggests that on- 
This is an author-produced, peer-reviewed version of this article. The final, definitive version of this document can be found online at Journal of Genetic Counseling, published by Wiley. Copyright restrictions may apply. https://doi.org/10.1002/jgc4.1213

the-job training in these technologies is more important for genetic counselors working in the laboratory setting. While laboratory counselors were significantly more likely to report bioinformatics more important to successful job performance than clinical counselors, bioinformatics scored among the lowest with regard to graduate school training. Bioinformatics is the tool used to analyze all genetic data; it is the language that translates the raw genetic data to understandable concepts and is therefore arguably the most important of any of the core technologies. This finding argues for improvement in education in bioinformatics in genetic counseling curricula and continuing education outlets, or that bioinformatics should be part of the standard onboarding training by diagnostic laboratories hiring genetic counselors.

Clinical genetic counselors were significantly more likely to feel that in-solution sequence capture methods were important for job performance compared to laboratory counselors. This finding may indicate that clinical counselors feel that complete knowledge of the strengths and limitations of capture methods and how they may influence gene coverage is necessary for proper patient counseling. On the other hand, it is possible that laboratory genetic counselors did not rank these technologies as important because they feel they are adequately trained in these methods which are commonly used by most diagnostic laboratories.

It stands to reason that genetic counselors in laboratory settings need to have in-depth knowledge of laboratory techniques. This study identified that fewer participants from the laboratory setting felt that graduate school training in NGS-based copy-number variation (CNV) detection was good compared to participants in the clinical setting. It is possible that this result is identifying laboratory genetic counselors' greater need for very nuanced and detailed understanding of this laboratory technology compared to clinical genetic counselors and in this regard the level of graduate school training for this GT was more suitable for clinical settings than laboratory settings.

It is interesting that most of the statistical analyses comparing laboratory, clinical, and other job settings did not reveal significance (Table 2). One might expect laboratory counselors to feel more knowledgeable about GT technologies. However, laboratory counselors work in a variety of settings (clinical reporting, research, marketing, accessioning, etc) and it is possible that some may have even less exposure to technologies than clinical counselors. Further, it is possible that the distinction in knowledge between laboratory and clinical counselors is blurred by the recent growth in the proportion of laboratory counselors in the workforce, many of whom spent the better part of their careers in the clinic.

Respondents from more recent graduating classes felt that graduate school training of GT was more adequate compared with respondents from the most senior graduating classes, who felt that training in virtually all of the technologies was poor or absent. This finding is expected given that several of the technologies did not exist for the earlier graduating classes. The data provide a glimpse into the education received among current, working genetic counselor professionals in a field that is rapidly advancing. Even among the classic genomic technologies of PCR/DNA amplification and Sanger Sequencing, over half of participants from the most senior graduating classes responded that training was inadequate. Despite these relative differences, it is worth noting that even among the most recent graduates roughly one-third reported that training was inadequate on average across all technologies. The desire for additional and on-going training opportunities regarding emerging GTs was expressed in respondent free text comments and suggestions as well. It appears that some respondents felt that rapid technology development is outpacing the ability for genetic counselors to obtain adequate training for appropriate and responsible use of emerging GTs in the clinic.

These data may also reflect a true paradigm shift in the scope of practice for genetic counseling in the United States and Canada The field of genetic counseling grew from a primarily prenatal specialty with far more attention on the psychosocial skill development as GT was comparatively simple, with fewer testing options. Although the data here indicate that GT education was inadequately met in earlier years, the need for in-depth understanding of a variety of GTs was also not quite as involved as it is currently. Now, with so many more technology options and expanding knowledge of molecular genetics, the need for genetic counselors to translate this complex information into practical clinical applications has grown and strategies to support this need must be developed.

One strategy for adapting to the need for in-depth understanding of clinical molecular diagnostic technologies involves genetic counselor specialization, where clinical counselors can leverage the knowledge of their laboratory colleagues when technical complexities arise and laboratory counselors can leverage counseling expertise of the clinical counselors. Another strategy is to lengthen the two-year genetic counseling program and/or develop specialization certifications. Benefits of a doctoral degree in genetic counseling have been presented since the 1980s (Scott, Walker, 
This is an author-produced, peer-reviewed version of this article. The final, definitive version of this document can be found online at Journal of Genetic Counseling, published by Wiley. Copyright restrictions may apply. https://doi.org/10.1002/jgc4.1213

Eunpu, \& Djurdjinovic, 1988) and early studies showed that most genetic counselors supported a doctoral degree in genetic counseling (Gaupman, Edwards, Brooks, \& Young, 1991). More recently, a 2015 survey assessing the attitudes of genetic counselors around the shifting of genetic counseling education to a clinical doctorate (ClinD) reported that most genetic counselors prefer to maintain the master's degree route (Nagy et al., 2015) and employees have concerns about the economic viability of a ClinD (Valverde, Mueller, Paciotti, \& Conway, 2016). Notably however, graduates from 2009-2012, who would have had the most exposure to newer and emerging GTs in that sample, were in favor of the ClinD significantly more than earlier graduating classes. Additional studies show that a majority of genetic counseling program directors are in favor of the transition to the clinical doctorate (Stuenkel, Campion, Allain, \& Hampel, 2012) and genetic counselors who already have doctoral degrees (PhD) see benefit to doctoral training in genetic counseling (Atzinger et al., 2007). Additionally, for a few measures in this present study, there is a divergence in terms of knowledge needs for clinical versus non-clinical genetic counselors. Perhaps an additional year would allow students to focus and have more time to develop the skills necessary for a particular specialty. Some training programs may also welcome the opportunity to have more space to teach new material while still honoring the relevant history of this profession.

One of the difficulties faced by training programs is trying to incorporate the new knowledge with the old. There is a far greater volume of genetic information today than even in recent years, and this body of knowledge will only continue to grow. It can be incredibly cumbersome and time consuming for academic institutions to continuously update curricula especially with subjects that are rapidly changing and become outdated in such little time. Furthermore, writing and validating questions for the national American Board of Genetic Counseling (ABGC) certification exam content also requires considerable time and effort. As a result, there may be required topics in genetic counseling training that center on longstanding practices that have become less emphasized in practice but need to be covered due to the challenges of quickly update curricula and ABGC proficiency standards. As a profession, it may be worth evaluating a new model for reviewing and deploying education standards in a manner that can keep up with a technologically advanced discipline like genetic counseling. In a thoughtful commentary, Hooker, et al. provide a diversity of approaches to maximizing genetic counseling education to include genomic medicine (Hooker et al., 2014).

In addition, it may be worthwhile to explore other methods for educating students through online technology solutions or multi-program collaborations. For example, training programs could adopt the same learning module, developed and shared with all ACGC accredited programs, on an emerging topic thus saving the same effort in creating similar content across the $>40$ currently accredited programs. More discussion would be necessary on the financial aspects of shared curriculum and tuition, but there may be opportunities to create some efficiency and standardization in genetic counseling training.

Given the rapid emergence of new genomic technologies and their equally rapid application to clinical testing, it is not realistic to expect graduate schools to provide a complete and thorough education of GT. However, efforts can be made to assist students with tools needed to continually identify available resources and educate themselves regarding advancements in newer technologies. As an example, some laboratories are currently offering remote learning opportunities which often include GT education to graduate students at no cost. Additionally, the results of this survey may help guide graduate programs in identifying the core genomic technology(s) deemed important for job success across disciplines. This may require programs to allocate more resources and additional time to ensure adequate student training.

The main source of continuing education for genetic counselors in the United States, the NSGC Annual Conference, encompasses a wide variety of topics covering clinical best practices and emerging research, and has gradually increased the number and depth of sessions provided by laboratories which include elements of genomic technology education. Interestingly, there was entire education session at the 2015 annual conference dedicated to bioinformatics, which may partially explain the low perceived need for additional training in bioinformatics found in this survey. While a great source for continuing GT education, the annual conference cannot suffice alone and additional resources throughout the rest of the year should be devoted to fill the knowledge gaps. As an example of ongoing GT education efforts, the NSGC GT SIG was founded in 2015 with the mission to promote the education of genetic counselors and other health care providers about existing, new, and emerging genetics and genomics technologies. The results of this survey have directly guided the GT SIG in prioritization of continuing education topics. 
This is an author-produced, peer-reviewed version of this article. The final, definitive version of this document can be found online at Journal of Genetic Counseling, published by Wiley. Copyright restrictions may apply. https://doi.org/10.1002/jgc4.1213

\section{$\underline{\text { Study Limitations }}$}

The survey was sent to the entire NSGC membership listerv and was also distributed to the GT and Cancer SIG listervs. However, the survey was emphasized within the GT SIG member listerv and some discussion and anticipation about the survey may have resulted in an overrepresentation of GT SIG members, who are likely to have more exposure and experience with GT than the general membership. This potential overrepresentation suggests that the true state of the need for GT education among genetic counselors is actually greater than the results indicate.

The estimated response rate (4.6\%) was low, however, the demographics are not statistically significant from the PSS survey, suggesting that the respondents were representative of the targeted population. However, the small sample size may have resulted in lack of power to detect statistically significant differences in GT responses across practice settings.

Another limitation of the study is the lack of a write-in option to potentially identify additional technologies outside of the twelve core GT or a question about any continuing education that had been received. Additionally, the data collected are all self-assessments and not based on a quantitative measurement of current knowledge of GT. Further, the comparison among graduation year may be inherently biased in that the survey was not administered immediately post-graduation. Those in more recent graduating years may have better recall of their educational experiences than those who graduated further in the past.

We would also like to point out that the survey was conducted three years ago, and the extent of gaps in knowledge of GT during the past few years is unknown. These data can be used as a starting point for additional, more in-depth research into GT educational needs of genetic counselors.

\section{Practice Implications}

It is fundamental to the success of a genetic counselor to have a thorough understanding of genetics and genomics (www.abgc.net/for-diplomates/practice-standards/). These data highlight the need for a more in-depth follow-up study which addresses the limitations of the current study and that can more adequately reflect the current state of genetic counseling graduate school education in the United States and Canada. Regardless, these results have implications for training programs and sources of ongoing education opportunities for genetic counselors as well as potentially for employers hiring genetic counselors with regard to genomic technology training gaps and opportunities for continuing education. It is likely that all geneticist, including $\mathrm{PhD}$ molecular geneticists and MD clinical geneticists have the same training needs given the rapid emergence of new technologies. Collaboration between NSGC, the American College of Medical Genetics, the American Society of Human Genetics, the Association for Molecular Pathology, and other organizations to offer continuing education would be beneficial.

\section{$\underline{\text { Conclusion }}$}

In this study, we present the first dataset demonstrating genetic counselors' self-assessment regarding GT knowledge gaps and training needs. The data show that genetic counselors overall report that their knowledge of GTs is lacking and yet a key component of their jobs.

Given the continuous, rapid emergence of new genomic technologies, genetic counseling graduate school programs cannot be expected to provide education in the newest technologies, Rather, programs can provide the fundamental basis of molecular technologies and prepare students for a career that includes continual learning. Continuing education efforts should focus heavily on GT. The GT SIG is one example of continuing education efforts. However, it should be noted that professional organization SIGs may be limited by budgetary constraints. Large-scale continuing education will likely take a significant coordinated effort by genetic counseling programs, NSGC, and other organizations (e.g. laboratories). 
This is an author-produced, peer-reviewed version of this article. The final, definitive version of this document can be found online at Journal of Genetic Counseling, published by Wiley. Copyright restrictions may apply. https://doi.org/10.1002/jgc4.1213

\section{Acknowledgements}

We'd like to thank the participants who took the time to answer the survey questions and provide comments.

\section{Conflict of Interest}

Kelly D. Farwell Hagman, Devon Lamb Thrush, Darnelle L. Dorsainville, and Kimberly C. Banks are employed in diagnostic laboratories. Samantha Freeze and Jennifer Eichmeyer declare they have no conflict of interest

\section{Human Studies and Informed Consent}

The research is exempt from the Office for Human Research Protections Regulations for the Protection of Human Subjects under category 46.104(A).

\section{Animal Studies}

No non-human animal studies were carried out by the authors of this article.

\section{Authorship Contributions}

Substantial contributions to the conception or design of the work; or the acquisition, analysis, or interpretation of data for the work was provided by Kelly D. Farwell Hagman, Devon Lamb Thrush, Samantha Freeze, Darnelle L. Dorsainville, Jennifer Eichmeyer, and Kimberly C. Banks.

Drafting the work or revising it critically for important intellectual content was provided by Kelly D. Farwell Hagman, Devon Lamb Thrush, Samantha Freeze, Darnelle L. Dorsainville, Jennifer Eichmeyer, and Kimberly C. Banks.

Final approval of the version to be published was provided by Kelly D. Farwell Hagman, Devon Lamb Thrush, Samantha Freeze, Darnelle L. Dorsainville, Jennifer Eichmeyer, and Kimberly C. Banks.

Agreement to be accountable for all aspects of the work in ensuring that questions related to the accuracy or integrity of any part of the work are appropriately investigated and resolved was provided by Kelly D. Farwell Hagman and Kimberly C. Banks. 
This is an author-produced, peer-reviewed version of this article. The final, definitive version of this document can be found online at Journal of Genetic Counseling, published by Wiley. Copyright restrictions may apply. https://doi.org/10.1002/jgc4.1213

\section{References}

Atzinger, C. L., Blough-Pfau, R., Kretschmer, L., Huether, C. A., Johnson, J. A., \& Warren, N. S. (2007). Characterization of the practice and attitudes of genetic counselors with doctoral degrees. J Genet Couns, 16(2), 223-239. doi:10.1007/s10897-006-9062-3

Baars, M. J., Henneman, L., \& Ten Kate, L. P. (2005). Deficiency of knowledge of genetics and genetic tests among general practitioners, gynecologists, and pediatricians: a global problem. Genet Med, 7(9), 605-610. doi:10.109701.gim.0000182895.28432.c7

Bamshad, M. J., Magoulas, P. L., \& Dent, K. M. (2018). Genetic counselors on the frontline of precision health. Am J Med Genet C Semin Med Genet, 178(1), 5-9. doi:10.1002/ajmg.c.31610

Blaine, S. M., Carroll, J. C., Rideout, A. L., Glendon, G., Meschino, W., Shuman, C., . . Permaul, J. (2008). Interactive genetic counseling role-play: a novel educational strategy for family physicians. J Genet Couns, 17(2), 189-195. doi:10.1007/s10897-007-9142-z

Calzone, K. A., Cashion, A., Feetham, S., Jenkins, J., Prows, C. A., Williams, J. K., \& Wung, S.-F. (2010). Nurses transforming health care using genetics and genomics. Nursing outlook, 58(1), 26-35. doi:10.1016/j.outlook.2009.05.001

Christian, S., Lilley, M., Hume, S., Scott, P., \& Somerville, M. (2012). Defining the role of laboratory genetic counselor. J Genet Couns, 21(4), 605-611. doi:10.1007/s10897-011-9419-0

Cunha, A. (2017). Genomic technologies-from tools to therapies. Genome Med, 9(1), 71. doi:10.1186/s13073-017$0462-9$

Farndon, P. A., \& Bennett, C. (2008). Genetics education for health professionals: strategies and outcomes from a national initiative in the United Kingdom. J Genet Couns, 17(2), 161-169. doi:10.1007/s10897-007-9144-x

Gaff, C. L., Williams, J. K., \& McInerney, J. D. (2008). Genetics in health practice and education special issue. J Genet Couns, 17(2), 143-144. doi:10.1007/s10897-008-9149-0

Galas, D. J., \& McCormack, S. J. (2003). An historical perspective on genomic technologies. Curr Issues Mol Biol, 5(4), 123-127.

Gaupman, K. M., Edwards, J. G., Brooks, K. A., \& Young, S. R. (1991). ASHG/NSGC activities related to education. The doctoral degree in genetic counseling: attitudes of genetic counselors. Am J Hum Genet, 49(2), 488-493.

Hooker, G. W., Ormond, K. E., Sweet, K., \& Biesecker, B. B. (2014). Teaching genomic counseling: preparing the genetic counseling workforce for the genomic era. J Genet Couns, 23(4), 445-451. doi:10.1007/s10897014-9689-4

Hunter, A., Wright, P., Cappelli, M., Kasaboski, A., \& Surh, L. (1998). Physician knowledge and attitudes towards molecular genetic (DNA) testing of their patients. Clin Genet, 53(6), 447-455. doi:10.1111/j.13990004.1998.tb02593.x

Kirk, M., Tonkin, E., \& Burke, S. (2008). Engaging nurses in genetics: the strategic approach of the NHS National Genetics Education and Development Centre. J Genet Couns, 17(2), 180-188. doi:10.1007/s10897-0079127-y

Masny, A., Ropka, M. E., Peterson, C., Fetzer, D., \& Daly, M. B. (2008). Mentoring nurses in familial cancer risk assessment and counseling: lessons learned from a formative evaluation. J Genet Couns, 17(2), 196-207. doi:10.1007/s10897-007-9140-1

McWalter, K., Cho, M. T., Hart, T., Nusbaum, R., Sebold, C., Knapke, S., . . Juusola, J. (2018). Genetic counseling in industry settings: Opportunities in the era of precision health. Am J Med Genet C Semin Med Genet, 178(1), 46-53. doi:10.1002/ajmg.c.31606

Metcalfe, A., Haydon, J., Bennett, C., \& Farndon, P. (2008). Midwives' view of the importance of genetics and their confidence with genetic activities in clinical practice: implications for the delivery of genetics education. $J$ Clin Nurs, 17(4), 519-530. doi:10.1111/j.1365-2702.2007.01884.x

Mikat-Stevens, N. A., Larson, I. A., \& Tarini, B. A. (2015). Primary-care providers' perceived barriers to integration of genetics services: a systematic review of the literature. Genet Med, 17(3), 169-176. doi:10.1038/gim.2014.101

Nagy, R., Peay, H., Hicks, M., Kloos, J., Westman, R., Conway, L., . . Reiser, C. (2015). Genetic Counselors' and Genetic Counseling Students' Attitudes Around the Clinical Doctorate and Other Advanced Educational Options for Genetic Counselors: A Report from the Genetic Counseling Advanced Degree Task Force. $J$ Genet Couns, 24(4), 626-634. doi:10.1007/s10897-014-9785-5

Profato, J., Gordon, E. S., Dixon, S., \& Kwan, A. (2014). Assessing the integration of genomic medicine in genetic counseling training programs. J Genet Couns, 23(4), 679-688. doi:10.1007/s10897-013-9677-0 
This is an author-produced, peer-reviewed version of this article. The final, definitive version of this document can be found online at Journal of Genetic Counseling, published by Wiley. Copyright restrictions may apply. https://doi.org/10.1002/jgc4.1213

Radford, C., Prince, A., Lewis, K., \& Pal, T. (2014). Factors which impact the delivery of genetic risk assessment services focused on inherited cancer genomics: expanding the role and reach of certified genetics professionals. J Genet Couns, 23(4), 522-530. doi:10.1007/s10897-013-9668-1

Roche, M. I. (2012). Moving toward NextGenetic counseling. Genet Med, 14(9), 777-778. doi:10.1038/gim.2012.84

Scott, J. A., Walker, A. P., Eunpu, D. L., \& Djurdjinovic, L. (1988). Genetic counselor training: a review and considerations for the future. Am J Hum Genet, 42(1), 191-199.

Stuenkel, A. J., Campion, M., Allain, D., \& Hampel, H. (2012). Transition to the clinical doctorate: attitudes of the genetic counseling training program directors in North America. J Genet Couns, 21(1), 136-149. doi:10.1007/s10897-011-9407-4

Suchard, M. A., Yudkin, P., Sinsheimer, J. S., \& Fowler, G. H. (1999). General practitioners' views on genetic screening for common diseases. Br J Gen Pract, 49(438), 45-46.

Swanson, A., Ramos, E., \& Snyder, H. (2014). Next Generation sequencing is the impetus for the next generation of laboratory-based genetic counselors. J Genet Couns, 23(4), 647-654. doi:10.1007/s10897-013-9684-1

Tandy-Connor, S., Guiltinan, J., Krempely, K., LaDuca, H., Reineke, P., Gutierrez, S., . . Tippin Davis, B. (2018). False-positive results released by direct-to-consumer genetic tests highlight the importance of clinical confirmation testing for appropriate patient care. Genet Med, 20(12), 1515-1521. doi:10.1038/gim.2018.38

Valverde, K., Mueller, R., Paciotti, B., \& Conway, L. (2016). An Exploratory Study of Employers' Attitudes Towards a Clinical Doctorate in Genetic Counseling. J Genet Couns, 25(1), 179-188. doi:10.1007/s10897015-9856-2

Wain, K. (2018). A Commentary on Opportunities for the Genetic Counseling Profession through Genomic Variant Interpretation: Reflections from an Ex-Lab Rat. J Genet Couns, 27(4), 747-750. doi:10.1007/s10897-018$0247-3$

Wicklund, C., \& Trepanier, A. (2014). Adapting genetic counseling training to the genomic era: more an evolution than a revolution. J Genet Couns, 23(4), 452-454. doi:10.1007/s10897-014-9690-y

Zetzsche, L. H., Kotzer, K. E., \& Wain, K. E. (2014). Looking back and moving forward: an historical perspective from laboratory genetic counselors. J Genet Couns, 23(3), 363-370. doi:10.1007/s10897-013-9670-7 
This is an author-produced, peer-reviewed version of this article. The final, definitive version of this document can be found online at Journal of Genetic Counseling, published by Wiley. Copyright restrictions may apply. https://doi.org/10.1002/jgc4.1213

\section{Table 1: Respondent Demographics}

\begin{tabular}{|c|c|c|}
\hline & $\mathbf{N}$ & $\%$ \\
\hline \multicolumn{3}{|l|}{ Primary Work Setting } \\
\hline Clinical Setting & 89 & $52.0 \%$ \\
\hline University Medical Center & 33 & $19.3 \%$ \\
\hline Public Hospital/Medical Facility & 28 & $16.4 \%$ \\
\hline Private Hospital/Medical Facility & 25 & $14.6 \%$ \\
\hline Physician's Private Practice & 3 & $1.8 \%$ \\
\hline Laboratory Setting & 62 & $36.3 \%$ \\
\hline Other & 20 & $11.7 \%$ \\
\hline Not-For-Profit Organization & 5 & $2.9 \%$ \\
\hline \multicolumn{3}{|l|}{ Research Development/Biotechnology } \\
\hline Company & 4 & $2.3 \%$ \\
\hline Bioinformatics Company & 2 & $1.2 \%$ \\
\hline University/Non-Medical Center & 2 & $1.2 \%$ \\
\hline Internet/Website Company & 2 & $1.2 \%$ \\
\hline Health Maintenance Organization & 2 & $1.2 \%$ \\
\hline Government Organization or Agency & 2 & $1.2 \%$ \\
\hline Private Practice Self-Employed & 1 & $0.6 \%$ \\
\hline \multicolumn{3}{|l|}{ Graduation Year } \\
\hline $1979-1989$ & 11 & $6.4 \%$ \\
\hline $1990-1999$ & 19 & $11.1 \%$ \\
\hline $2000-2009$ & 68 & $39.8 \%$ \\
\hline $2010-2015$ & 73 & $42.7 \%$ \\
\hline
\end{tabular}


Table 2: Summary of Responses Regarding the Core Technologies by Job Specialty

\begin{tabular}{|c|c|c|c|c|c|c|c|c|c|c|c|c|}
\hline \multirow[b]{2}{*}{ Job setting } & \multicolumn{4}{|c|}{$\begin{array}{l}\text { Deemed important to successful job performance }{ }^{\mathrm{a}, \mathrm{d}} \\
\text { No. (\%) }\end{array}$} & \multicolumn{4}{|c|}{$\begin{array}{l}\text { At least some training needed to successfully } \\
\text { perform job } \\
\text { No. }(\%)\end{array}$} & \multicolumn{4}{|c|}{$\begin{array}{l}\text { Graduate school training was good }{ }^{c, d} \\
\text { No. (\%) }\end{array}$} \\
\hline & Clinical $^{e}$ & Laboratoy & Other ${ }^{f}$ & Total & Clinical $^{e}$ & Laboratoy & Other $^{f}$ & Total & Clinical $^{e}$ & Laboratoy & Other ${ }^{f}$ & Total \\
\hline Next-gen sequencing & 87 (97.8\%) & $62(100 \%)$ & $20(100 \%)$ & $\begin{array}{c}169 \\
(98.8 \%)\end{array}$ & $33(37.9 \%)$ & 25 (41.0\%) & $14(70.0 \%)$ & $72(42.9 \%)$ & 26 (30.2\%) & $8(12.9 \%)$ & $6(30.0 \%)$ & $40(23.4 \%)$ \\
\hline Sanger Sequencing & 85 (95.5\%) & $58(93.5 \%)$ & $18(90.0 \%)$ & $\begin{array}{c}161 \\
(94.2 \%)\end{array}$ & 36 (41.9\%) & 29 (48.3\%) & $6(30.0 \%)$ & $71(42.8 \%)$ & 70 (82.4\%) & 36 (58.1\%) & 11 (57.9\%) & $\begin{array}{c}117 \\
(68.4 \%)\end{array}$ \\
\hline cell free DNA (cfDNA): Tumor & $80(89.9 \%)$ & 59 (95.2\%) & $20(100 \%)$ & $\begin{array}{c}159 \\
(93.0 \%)\end{array}$ & $68(78.2 \%)$ & $44(71.0 \%)$ & $18(90.0 \%)$ & $\begin{array}{c}130 \\
(76.9 \%)\end{array}$ & $1(1.2 \%)$ & $3(4.8 \%)$ & $1(5.0 \%)$ & $5(2.9 \%)$ \\
\hline $\begin{array}{l}\text { Pre-implantation genetic diagnosis/ } \\
\text { screening (PGD/PGS) }\end{array}$ & $\begin{array}{c}63 \\
(74.1 \%)^{9}\end{array}$ & $\begin{array}{c}60 \\
(98.4 \%)^{9}\end{array}$ & $16(84.2 \%)$ & $\begin{array}{c}139 \\
(84.2 \%)\end{array}$ & 67 (77.9\%) & $42(68.9 \%)$ & 15 (78.9\%) & $\begin{array}{c}124 \\
(74.7 \%)\end{array}$ & 40 (46.5\%) & 33 (53.2\%) & $8(40.0 \%)$ & $81(47.4 \%)$ \\
\hline $\begin{array}{l}\text { Multiplex Ligation-dependent Probe } \\
\text { Amplification (MLPA) }\end{array}$ & 67 (75.3\%) & $54(87.1 \%)$ & 17 (85.0\%) & $\begin{array}{c}138 \\
(80.7 \%)\end{array}$ & 49 (55.1\%) & $\begin{array}{c}28 \\
(45.2 \%)^{9}\end{array}$ & $\begin{array}{c}17 \\
(85.0 \%)^{9}\end{array}$ & $94(55.0 \%)$ & 33 (38.4\%) & 15 (24.2\%) & $4(20.0 \%)$ & $52(30.4 \%)$ \\
\hline PCR/ DNA amplification & 71 (79.8\%) & $51(83.6 \%)$ & $15(75.0 \%)$ & $\begin{array}{c}137 \\
(80.6 \%)\end{array}$ & $63(72.4 \%)$ & $44(71.0 \%)$ & 15 (75.0\%) & $\begin{array}{c}122 \\
(72.2 \%)\end{array}$ & $66(77.6 \%)$ & 37 (59.7\%) & $10(50.0 \%)$ & $\begin{array}{c}113 \\
(66.1 \%)\end{array}$ \\
\hline $\begin{array}{l}\text { NGS-based copy-number variation (CNV) } \\
\text { detection }\end{array}$ & 64 (74.4\%) & $51(83.6 \%)$ & $17(85.0 \%)$ & $\begin{array}{c}132 \\
(79.0 \%)\end{array}$ & $66(75.9 \%)$ & 45 (72.6\%) & $16(80.0 \%)$ & $\begin{array}{c}127 \\
(75.1 \%)\end{array}$ & $\begin{array}{c}21 \\
(24.4 \%)^{9}\end{array}$ & $3(4.9 \%)^{9}$ & $4(20.0 \%)$ & $28(16.4 \%)$ \\
\hline On-array sequence capture methods & 59 (68.6\%) & 30 (48.4\%) & $16(80.0 \%)$ & $\begin{array}{c}105 \\
(62.5 \%)\end{array}$ & $24(27.0 \%)$ & $16(26.2 \%)$ & $8(40.0 \%)$ & $48(28.2 \%)$ & $9(10.6 \%)$ & $6(9.8 \%)$ & $3(15.0 \%)$ & $18(10.5 \%)$ \\
\hline In-solution sequence capture methods & $\begin{array}{c}63 \\
(70.8 \%)^{9}\end{array}$ & $\begin{array}{c}25 \\
(40.3 \%)^{9}\end{array}$ & $13(68.4 \%)$ & $\begin{array}{c}101 \\
(59.4 \%)\end{array}$ & $48(54.5 \%)$ & $33(53.2 \%)$ & $14(70.0 \%)$ & $95(55.9 \%)$ & $5(5.9 \%)$ & $3(4.8 \%)$ & $1(5.0 \%)$ & $9(5.3 \%)$ \\
\hline
\end{tabular}




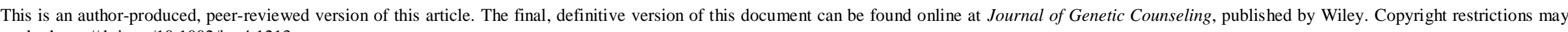
apply. https://doi.org/10.1002/jgc4.1213

\begin{tabular}{|c|c|c|c|c|c|c|c|c|c|c|c|c|}
\hline $\begin{array}{l}\text { cell free DNA (cfDNA): Non-invasive } \\
\text { prenatal testing/screening (NIPT/NIPS) }\end{array}$ & 47 (53.4\%) & 29 (46.8\%) & $12(60.0 \%)$ & $88(51.8 \%)$ & 28 (32.9\%) & 29 (47.5\%) & $9(45.0 \%)$ & $66(39.8 \%)$ & $16(18.6 \%)$ & $10(16.1 \%)$ & $5(25.0 \%)$ & 31 (18.1\%) \\
\hline Comparative genomic hybridization (aCGH) & $\begin{array}{c}34 \\
(38.2 \%)^{g}\end{array}$ & $42(68.9 \%)^{9}$ & $11(55.0 \%)$ & 87 (51.2\%) & 59 (67.0\%) & 40 (65.6\%) & $14(70.0 \%)$ & $\begin{array}{c}113 \\
(66.9 \%)\end{array}$ & 39 (45.3\%) & 21 (34.4\%) & 8 (40.0\%) & 68 (39.8\%) \\
\hline Bioinformatics & $\begin{array}{c}26 \\
(29.5 \%)^{9}\end{array}$ & $\begin{array}{c}43 \\
(70.5 \%)^{9}\end{array}$ & 9 (45.0\%) & $78(46.2 \%)$ & 24 (27.3\%) & 18 (29.5\%) & 7 (35.0\%) & $49(29.0 \%)$ & $12(14.5 \%)$ & 2 (3.2\%) & 1 (5.0\%) & $15(8.8 \%)$ \\
\hline AVERAGE: & $70.6 \%$ & $76.4 \%$ & $77.3 \%$ & $73.5 \%$ & $54.0 \%$ & $53.3 \%$ & $64.1 \%$ & $54.9 \%$ & $33.0 \%$ & $23.9 \%$ & $26.3 \%$ & $28.1 \%$ \\
\hline
\end{tabular}

aResponse of either "very important" or "somewhat important"

bResponse of either "some training" or "a high level of training- I have no knowledge of this technology"

cResponse of either "very good" or "good"; response of N/A was not included

dNote that the number of respondents varied per question; the denominator is therefore different for each question

eUniversity Medical Center, Public or Private Hospital, Private Practice

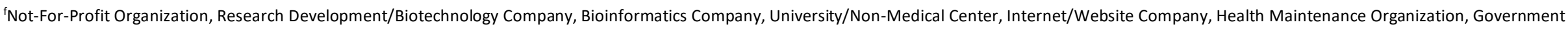
Organization or Agency, Private Practice Self-Employed

${ }_{\mathrm{g}}^{\mathrm{g}}<0.01$. (Fisher's exact $2 \times 2$ 2-tailed contingency); cells are shaded 
Table 3: Respondents Citing Inadequate Training in Graduate School For Each of the Core Technologies by Year of Graduation

\begin{tabular}{|c|c|c|c|c|}
\hline & $\begin{array}{c}\text { Graduated } 1979- \\
1989(n=11)\end{array}$ & $\begin{array}{c}\text { Graduated } \\
1990-1999 \\
(n=19)\end{array}$ & $\begin{array}{c}\text { Graduated } \\
2000-2009 \\
(n=68)\end{array}$ & $\begin{array}{c}\text { Graduated } \\
2010-2015 \\
(n=73)\end{array}$ \\
\hline cell free DNA (cfDNA): Non-invasive prenatal testing/screening (NIPT/NIPS) & $100.0 \%$ & $100.0 \%$ & $98.5 \%$ & $79.2 \%$ \\
\hline cell free DNA (cfDNA): Tumor & $100.0 \%$ & $100.0 \%$ & $98.5 \%$ & $38.9 \%$ \\
\hline In-solution sequence capture methods & $100.0 \%$ & $100.0 \%$ & $91.0 \%$ & $71.8 \%$ \\
\hline Next-gen sequencing & $100.0 \%$ & $94.4 \%$ & $89.6 \%$ & $29.2 \%$ \\
\hline On-array sequence capture methods & $100.0 \%$ & $94.4 \%$ & $85.1 \%$ & $58.6 \%$ \\
\hline NGS-based copy-number variation (CNV) detection & $100.0 \%$ & $94.4 \%$ & $83.3 \%$ & $45.8 \%$ \\
\hline Multiplex Ligation-dependent Probe Amplification (MLPA) & $100.0 \%$ & $94.4 \%$ & $49.3 \%$ & $27.8 \%$ \\
\hline Comparative genomic hybridization (aCGH) & $100.0 \%$ & $94.4 \%$ & $48.5 \%$ & $9.7 \%$ \\
\hline Bioinformatics & $100.0 \%$ & $83.3 \%$ & $79.1 \%$ & $60.0 \%$ \\
\hline Pre-implantation genetic diagnosis/ screening (PGD/PGS) & $100.0 \%$ & $55.6 \%$ & $19.4 \%$ & $15.3 \%$ \\
\hline PCR/ DNA amplification & $72.7 \%$ & $100.0 \%$ & $7.5 \%$ & $7.0 \%$ \\
\hline Sanger Sequencing & $54.5 \%$ & $27.8 \%$ & $4.5 \%$ & $5.6 \%$ \\
\hline AVERAGE: & $93.9 \%$ & $86.6 \%$ & $62.9 \%$ & $37.4 \%$ \\
\hline
\end{tabular}

aResponse of either "poor," "very poor," or "N/A - didn't receive training" 


\section{Table 4: Respondent Free Text Thematic Analysis}

\section{Qualitative Theme Retrieved from}

Respondent Free Text
Theme Definition
Respondents'

Reporting N (\%)

\section{Training Theme}

Specific training

Lack of training

Emerging technologies training

Practical training

On-the-job training
ADesire for additional GT training regarding specific GT (ex: cfDNA, tumor analysis, NGS, WES, WGS, microarray, MLPA, etc). Example: "I would love to learn about cell free tumor DNA. I never learned it in graduate school and I have recently heard of it at a conference for the first time."

Personal or perceived impression that GC training programs in general do not meet what they believe to be "standards of education" on GTs for working GCs. Example: "I definitely think more training is needing during grad school. Even the training I did receive in grad school was in the theory behind the testing without really applying it to real situation."

Personal or perceived desire for additional and on-going training opportunities to address new and emerging GTs. Example: "I feel very

Personal or perceived impression that GT training in GC training programs is not always practical or designed to encompass the knowledge actually needed for job performance (desire for less theoretical information and more practical application of GT knowledge) Example: "Had some education [regarding GTs], but at the time didn't know what was important for everyday use and what was background education, areas of importance are more clear now that I am in practice."

APersonal or perceived impression that most of the "useful" education about GTs is gained from on-the-job education and learning from other GCs. "I now work in a commercial laboratory and received most of my higher-level education about genomic technologies as part of my training for this job. There were very few training opportunities in graduate school or in clinical practice." uneducated about genetic technologies that have come out in the last 5 years."

$14 / 49(28.6 \%)$

$13 / 49(26.5 \%)$

\section{Comparison Ability Theme}

Technology comparison

Desire for additional GT training regarding evaluating clinical appropriateness of GTs as well as the differences between different platforms or different versions of the same GT. Example: "Training on the limitations of the different methods of clinical testing available would be helpful such as WES vs WGS, MLPA/array vs NGS for del/dup."

Personal or perceived desire for additional GT training regarding evaluating the strengths/weakness of labs and how to choose the "best lab" for the specific GT evaluated. Example: "Types of terminology commonly used in methodology section to help ID type of technology done regardless of the commercial name of the test." 


\section{Other Theme}

Lack of interest

Daunting

Regulation
Personal or perceived impression that GCs are generally disinterested in understanding or that GCs are intimidated by their lack of understanding of GT and therefore do not have an interest in GT. Example: "I need to understand the differences between them, the limitations and benefits of each, but most of my clients are not interested in having exhaustive detail of the technology, just an understanding of the significance for them."

Personal or perceived impression that although most GCs desire a more holistic understanding of GT, the complexity and sheer amount of information is daunting and preventative to seeking out additional training. Example: "Hard for me to follow the new technology."

Desire for additional GT training regarding various regulation principles surrounding GT (ex: FDA regulations, data protection, conflict of interest for lab GCs, etc.) Example: "Standards regulation including NSGC position and FDA role in regulations."

cfDNA = cell free DNA, NGS = next-generation sequencing, WES = whole exome sequencing, WGS = whole genome sequencing, MLPA = multiple ligation-depending probe amplification, GT = genomic technology, GC = genetic counselor 
This is an author-produced, peer-reviewed version of this article. The final, definitive version of this document can be found online at Journal of Genetic Counseling, published by Wiley. Copyright restrictions may apply. https://doi.org/10.1002/jgc4.1213

\section{Figure 1: Heat Map of Knowledge Importance and Training Needs by Genomic Technology (GT)}

\begin{tabular}{|c|c|c|c|c|}
\hline Genomic Technology & $\begin{array}{l}\text { Knowledge of GT is } \\
\text { important or } \\
\text { somewhat important } \\
\text { for successful job } \\
\text { performance }\end{array}$ & $\begin{array}{l}\text { Some or significant } \\
\text { training in GT is } \\
\text { needed to more } \\
\text { adequately perform } \\
\text { job }\end{array}$ & $\begin{array}{l}\text { Good or very good } \\
\text { training of GT } \\
\text { received in graduate } \\
\text { school }\end{array}$ & $\begin{array}{c}\text { Education } \\
\text { Need } \\
\text { Ranking }\end{array}$ \\
\hline cell free DNA (cfDNA): Tumor & $93.0 \%$ & $76.9 \%$ & $2.9 \%$ & 1 \\
\hline $\begin{array}{l}\text { NGS-based copy-number variation } \\
\text { (CNV) detection }\end{array}$ & $79.0 \%$ & $75.1 \%$ & $16.4 \%$ & 2 \\
\hline $\begin{array}{l}\text { Pre-implantation genetic diagnosis/ } \\
\text { screening (PGD/PGS) }\end{array}$ & $84.2 \%$ & $74.7 \%$ & $47.4 \%$ & 3 \\
\hline In-solution sequence capture & $59.4 \%$ & $55.9 \%$ & $5.3 \%$ & 4 \\
\hline Next-generation sequencing & $98.8 \%$ & $42.9 \%$ & $23.4 \%$ & 5 \\
\hline $\begin{array}{l}\text { Multiplex Ligation-dependent Probe } \\
\text { Amplification (MLPA) }\end{array}$ & $80.7 \%$ & $55.0 \%$ & $30.4 \%$ & 6 \\
\hline $\begin{array}{l}\text { Comparative genomic hybridization } \\
\qquad(\mathrm{aCGH})\end{array}$ & $51.2 \%$ & $66.9 \%$ & $39.8 \%$ & 7 \\
\hline $\begin{array}{l}\text { Polymerase chain rection (PCR)/ DNA } \\
\text { amplification }\end{array}$ & $80.6 \%$ & $72.2 \%$ & $66.1 \%$ & 8 \\
\hline $\begin{array}{l}\text { cell free DNA (cfDNA): Non-invasive } \\
\text { prenatal testing/screening (NIPT/NIPS) }\end{array}$ & $51.8 \%$ & $39.8 \%$ & $18.1 \%$ & 9 \\
\hline On-array sequence capture & $62.5 \%$ & $28.2 \%$ & $10.5 \%$ & 10 \\
\hline Sanger Sequencing & $94.2 \%$ & $42.8 \%$ & $68.4 \%$ & 11 \\
\hline Bioinformatics & $46.2 \%$ & $29.0 \%$ & $8.8 \%$ & 12 \\
\hline Greatest need (hig) & t rate for importance ar & raining need) or gap ( & $\%$ received training in $\varepsilon$ & d school) \\
\hline Next greatest need & lowledge, training need & r gap (15-30\% receive & aining in grad school) & \\
\hline $\begin{array}{l}\text { 3rd group by decre } \\
50 \%)\end{array}$ & ng rank (knowledge and & aining need moderate; & d school education rec & ed for 40- \\
\hline
\end{tabular}

